\title{
The Analysis 0f The Time Table Structure WITHIN A STUDENT INFORMATION SYSTEM (SIS)
}

\author{
Dr. Issa S. I. Ottoum \\ Department of Computer information system (CIS) Alzaytoonah University of Jordan \\ Amman, Jordan
}

\begin{abstract}
This paper will show the result of the analysis and synthesis processes that take place when making a time table for a University Information System (UIS), especially for SIS.This proposed paper does the comparison between two methods of designing a time table, shows the advantages and disadvantages of these methods and more precisely how to implement each of them using programming languages.
\end{abstract}

\section{KEYWORDS}

Student Information System (SIS), Time table, Prerequisite courses, Flowchart.

\section{INTRODUCTION}

The designing of time table still actual for any UIS, although that the university information system has many features which could be considered important and required for the staff, students and administration.

\section{Related Works}

As known the University Information System considers as the main part of any higher education institution. It has many features that of course bring a lot of benefits for staff and students, such as student registration process, admission policies curriculum, study plan, time table, e-learning and more others $[1,2,3,4,5,6,7]$.

This research work will be focused on comparing two methods for constructing time table as a part of Student Information System which is included within the university information system. Many researchers were working upon this problem and gave it the required attention and necessary efforts. AfifMghawish, in his work [16] was suggested a procedure FORECAST for solving time table problem. Developing constraints satisfaction problem model for time tabling problem was discussed and viewed by the research done by Zhang I. and Lau S. [9]. OZ Schaerd in his paper [15] classified time tabling into school timing, where the overlaps between courses are removed. 


\section{The proposed work}

This paper suggests the Time table as layer-structure that depicted as shown in this figure

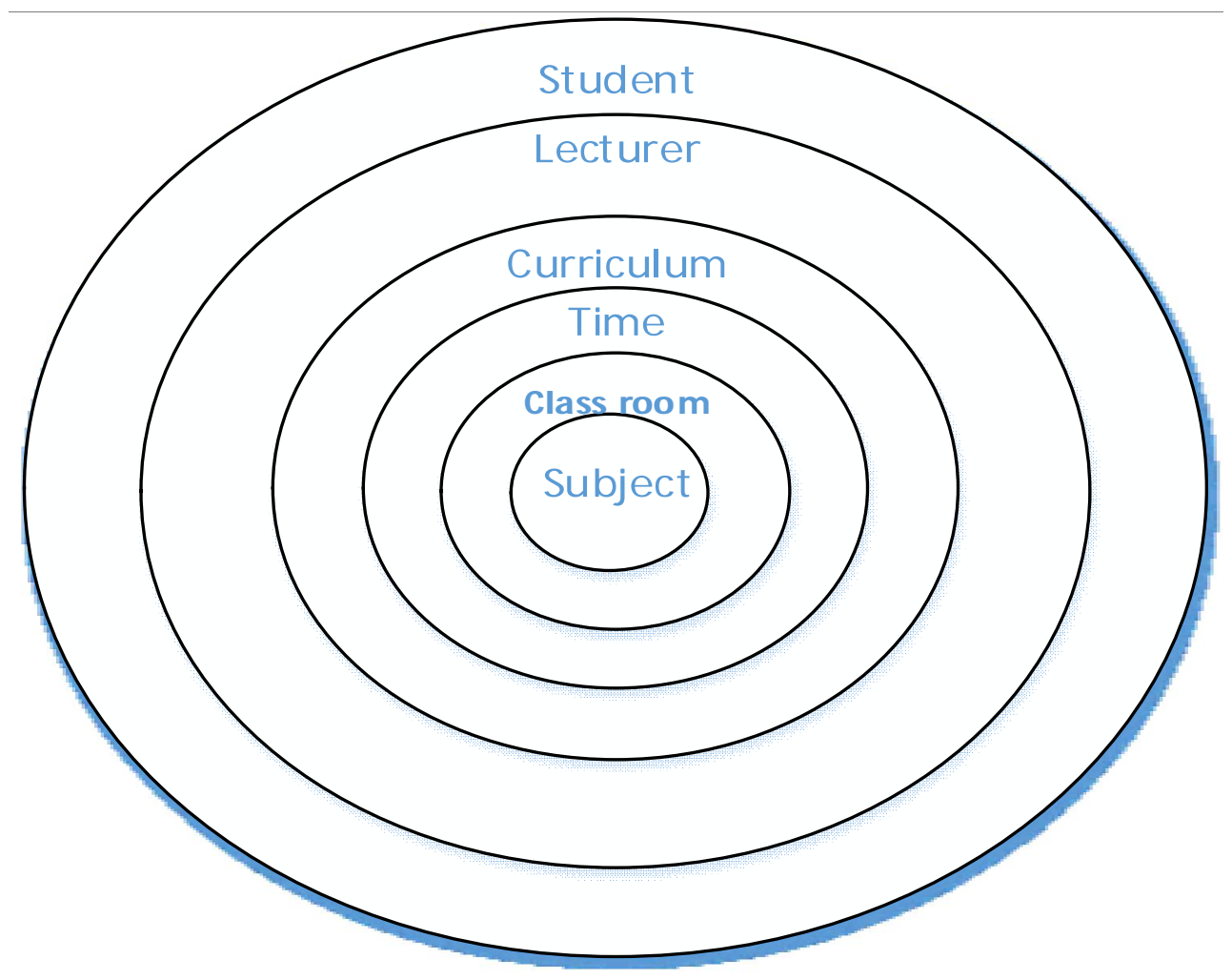

Figure1.Layer-structure for Time Table

As mentioned above in figure1, the layer-structure of the Time table is comprised of the following features:

- A core (level-0) which is represented by the "Subject".

- Level-1 that represents the "Class room".

- Level-2 is specified for time allocation "Time".

- Level-3 is occupied by "Curriculum".

- Level-4 for representing the "Lecturer".

- Level-5 for representing end-user "Student".

The interrelation amongthese six layers should be enough strong to obtain the required and desired results (Time table).

\section{Analysis of the Time table layer-structure}

The analysis of the Time table layer-structure can be simply done by looking at each level of the structure separately and then specifying the interrelationships among them. So, the required information for every level of the layer-structure obtained from the analysis process is summarized in table 1. 
Table 1 .The results of the analyzing process.

\begin{tabular}{|l|rl|}
\hline Levels & Analysis Results \\
\hline Level-0 & - & Prerequisite subject(s) \\
& - & Type of subject (elective, mandatory, faculty, department, university). \\
& - & Academic level of subject. \\
& - & Total number of sections for every subject. \\
\hline Level-1 & - & Type of class-room (labs, auditorium). \\
(Class-room) & - & Total number of class-room for each type. \\
& - & Capacity of every class-room. \\
\hline Level-2 & - & Slots of time (how many hours are allocated for each section?). \\
(Time) & - & Allowed total number of slots at a day. \\
& & \\
\hline Level-3 & - & Total number of subjects under-graduated study plan. \\
(Curriculum) & - & The credit hours for each subject. \\
& - & Subject number. \\
& - & Total number of subjects per a subject type. \\
\hline Level-4 & - & Defining the staff. \\
(Lecturer) & - & Total number of lecturers which could teach a specified subject. \\
& - & A convenient time for a lecturer. \\
\hline \multicolumn{1}{c|}{$\begin{array}{l}\text { Level-5 } \\
\text { (Student) }\end{array}$} & - & Total number of students. \\
& - & Total number of students that desired to take the subject in the next \\
& & term and they satisfied the conditions to register it. \\
\hline
\end{tabular}

\section{Methods to design a Time table}

Based on the information in table1, there are proposed two methods that can help in designing a time table.

The first method leads to do the schedule simply and artificial following these trivial steps:

1. Identifying timing slots per day.

2. Identifying class-rooms by their capacities.

3. Specifying the subjects and required sections for every subject.

The second method uses the same steps existing in the first method but more deeply and also adds other important steps that make the evolved schedule more efficient and more productive. These additional steps are:

- Before distribution courses and sections in corresponding to timing slots and class rooms some sub steps should be performed:

1. Specifying the prerequisite for each subject;

2. Confirm the number of students that passed these prerequisite courses;

3. Determining for each student how many courses had been passed or failed and how many courses have been not studied yet;

4. Determining the available number of lecturers for sections per every subject;

5. Specifying the level for all subjects [20]. 


\section{Implementation}

Every university has its own rules and practices when designing a time table. This research paper focuses on the design and implementation of a Student Information System as a core of the UIS. So the implementation of the two methods discussed above should be done taking into account the layer structure of the time table as shown below:

\section{Choose the subject}

Before writing sample programs as examples for proving the correctness and efficiency of the discussed methods above, the demonstration of some flowcharts that illustrate in details how to choose the subject:

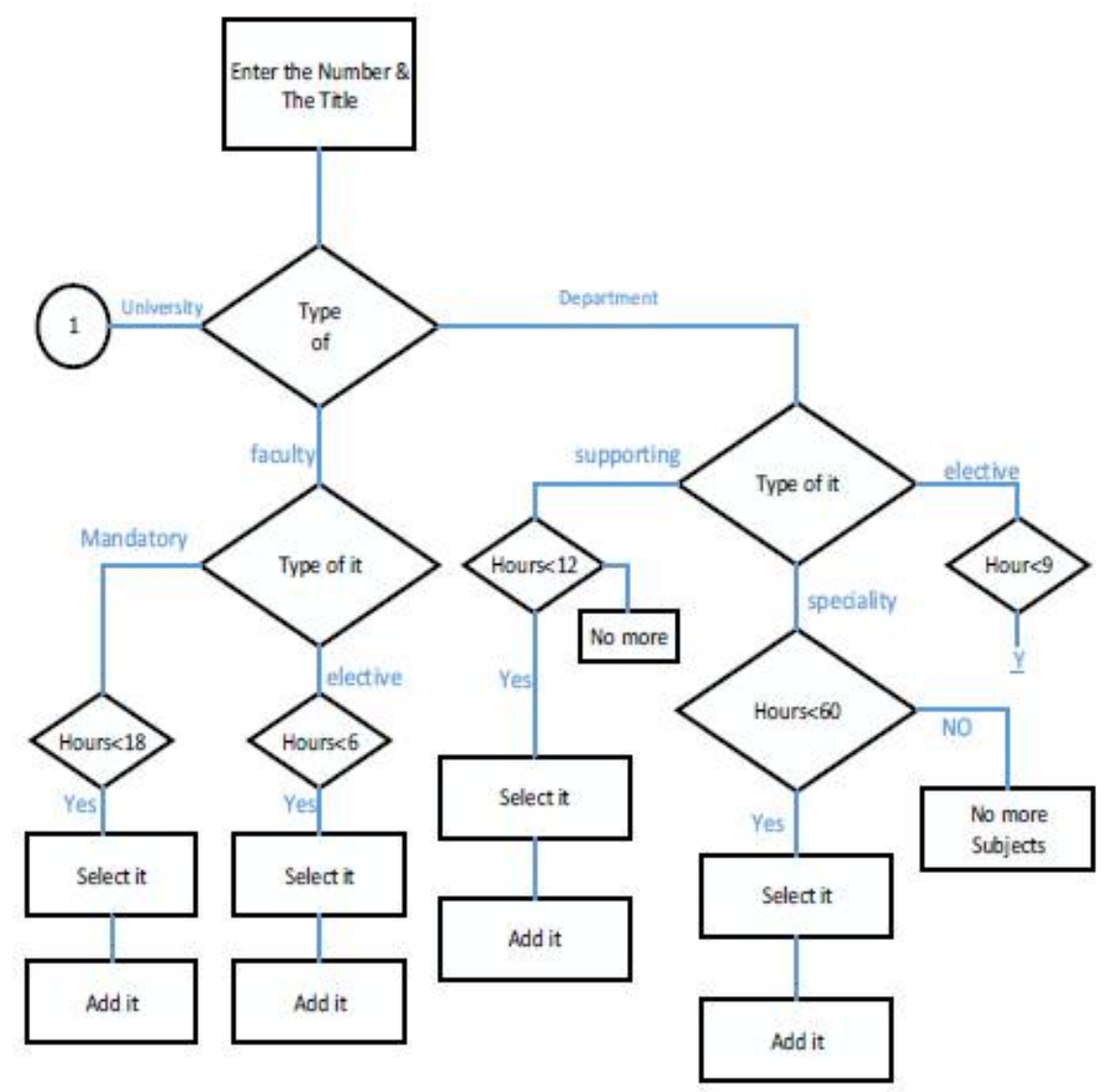




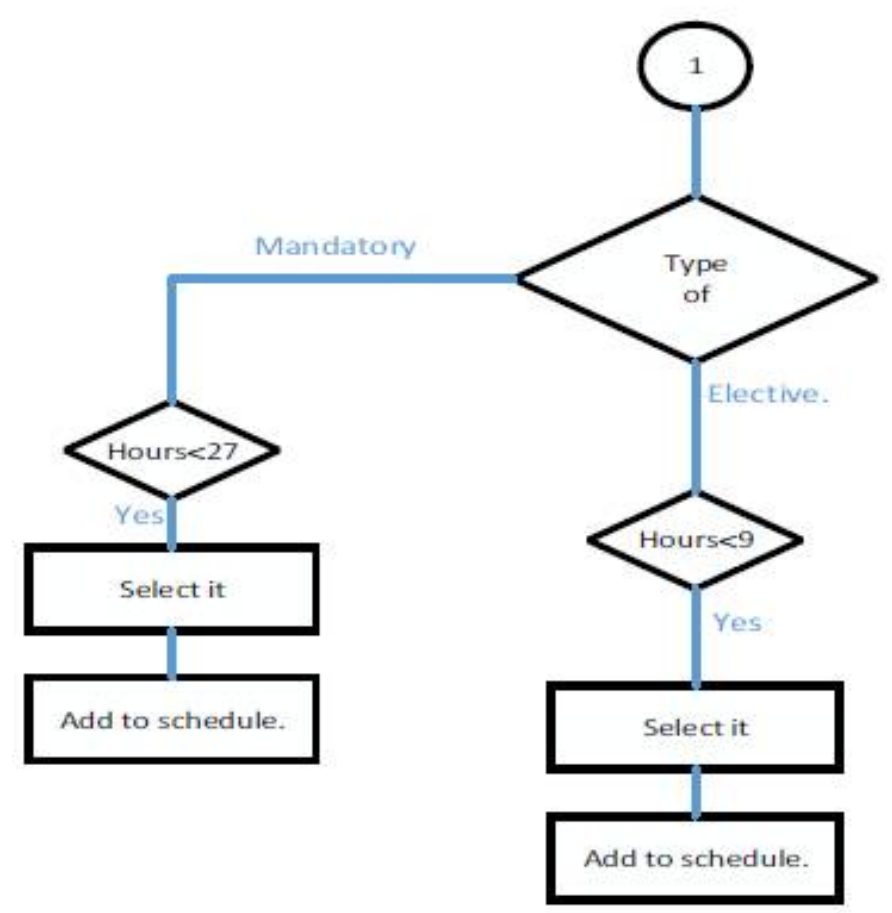

\section{DESIGN TIME AND CLASS ROOM TABLE}

The relationship between the times allocated for a schedule and the class rooms is so simple and might occur in a question form "how many free class rooms available at each time slot?", where the time slot means: the time required for one lecture. For example if the lecture for one hour, the time slot is also specified for one hour.

The time and class room is a two dimensional table of the form (see table.2 []).

Table. 2 the Time-Classroom Relationship.

\begin{tabular}{|l|l|l|l|l|}
\hline Classroom Time & Time-slot1 & Time-slot2 & $\ldots \ldots$ & Time-slot $(\mathrm{m})$ \\
\hline Classroom1 & & & $\ldots$ & \\
\hline Classroom2 & & & $\ldots$ & \\
\hline Classroom3 & & & & \\
\hline$\cdot$ & $\cdot$ & $\cdot$ & $\ldots \ldots$ & $\cdot$ \\
& $\cdot$ & $\cdot$ & & $\cdot$ \\
\hline Classroom(n-1) & & & $\ldots \ldots$ & \\
& & & $\ldots$ & \\
\hline Classroom(n) & & & $\ldots \ldots$ & \\
& & & $\ldots$ & \\
\hline
\end{tabular}

The total number of sections of different courses that might be scheduled equals nxm. 


\section{CURRICULUM}

The curriculum is the more important document when preparing a schedule, because it includes all the subjects and their perquisites required for graduation process, arranged in some particular order based on a block system, where each block is specified for certain subjects by relating to some criteria such as( university, faculty, department, mandatory, and elective).

\section{Choose the staff (lecturers)}

When choosing the lecturers for the different courses and sections, some criteria should be followed:

$>$ The total number of qualified lecturers must be satisfied to cover all the sections of different courses.

$>$ Take into account the convenient time for every lecturer as possible.

$>$ The number of sections for each lecturer must not exceed the specified load accredited by university rules.

\section{Design databases and writing programs}

For the above proposed methods a sample example was done by designing a proper database and writing a code. The results of this example shows that the time table has no overlaps between courses, facilitates the student registration process, gives attractive user interfaces and helps the staff in scheduling their times in a right way.

To assess the performance of the obtained outcome, we create the function so-called index function.

The index function is a function of many parameters with the following format:

INDEX(array, row_num, coloumn_num), where

1. array: Where is the list? The array can be organized either by an absolute reference as $(\$ A \$ 1: \$ D \$ 3)$, or by a relative reference as (A1:D3).

2. row_num: Which row has the value to be returned?

3. column_num: Which column has the value to be returned?

For the case discussed in this paper, the index function will take the following excel sheet:

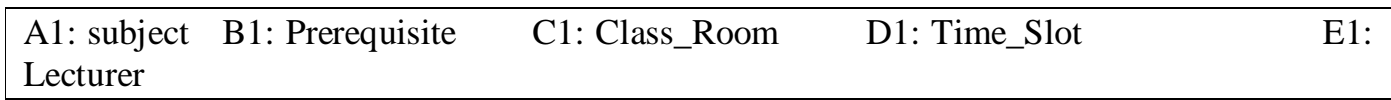

Writing a general formula by which the assessment will be done and then verifying it for some given data related to the time table problem, the result obtained by this indexed function shows that the proposed methods are worked correctly with high performance.

\section{CONCLUSION}

This paper concerned with the main ideas stand behind the constructing of the time table as a part of the Student Information System. Two methods of constructing were discussed and implemented as mentioned above. 
Comparing the results obtained by the two methods, it is clear that the second one reduces gaps occurred in the time table, makes students more flexible in selecting their subjects, increases efficiency of the departments and allows staff to better serve students. I used the studyhours course of Jordanian Al- Zaytoonah university, to determine the role of hours in research process

\section{REFERENCES}

[1] http:// www.bu.edu/reg (UIS of Boston University, USA).

[2] http://www.oibs.metu.edu.tr (UIS of Middle East Technical University, Turkey)

[3] http://www.utdallas.edu (UIS of University of Texas, USA)

[4] http://www.acs.utah.edu/student (UIS of University of Utah, USA)

[5] http://www.sisweb.uccavis.edu (UIS of University of California)

[6] http://www.registar.mit.edu (UIS of MIT, USA)

[7] http://www.epgy.stanford.edu (UIS of Stanford University, USA)

[9] Zhang, L., Lau, S. (2005). Constructing university timetable using constraint satisfaction programming approach. Proceedings of the International Conference on Computational Intelligence for Modeling, Control and Automation and International Conference on Intelligent Agents, Web Technologies and Internet Commerce Vol-2 ( CIMCA - IAWTIC'06 ), November 28 - 30 , p.55 - 60.

[10] Ho Sheau Fen, ET.al. (2009) University Course Timetable Planning using Hybrid Particle Swam Optimization. GEC'09 Proceedings of the First ACM / SIGEVO Summit on Generic and Evolutionary Computation, NY, USA, p.p. 239 - 246.

[11] Beck J.C., Davenport A.J., and Fox M.S. (1988) The ODO Project Towards a Unified Basis for Constraint-Directed Scheduling. International Journal of Scheduling, 1, p.p. 89 - 125.

[12] http://www.ttable.com (software package TTABLE)

[13] http://timetabler.com/tt4windows (software package TimeTabler4).

[14] Ossyka, A. Mghawish, A. Ottom, E. (2005) Computer-Aided Students Registration System. The Second International Conference on Information Technology ICIT-2005 (p.p. 291 - 297), Amman, Jordan.

[15] Francisco Azevedo and Pedro Barahona.Timetabling in constraint logic programming.In Proceedings of 2nd World Congress on Expert Systems, Estoril, Portugal, Jan 1994.

[16] Developing New Features for a University Information System Dr. Afif J. Almghawish Journal “ Science Series Data Report ", Vol.4, and No.12. Dec 2012, P.71 - 85.

[17] Supporting Student Information System Validity. Afif J. ALmghawish, Alexandre F. Ossyka, European Journal of Scientific Research Vol.99, No.2 April 2013.

[18] Andrea Schaerf. A survey of automated timetabling. Artificial Intelligence Review, 13(2):87 - 127, 1999.

[19] Martin Henz and JörgWürtz.Using Oz for college timetabling. In Proceedings of the 1995 International Conference on the Practice and Theory of Automated Timetabling, Edinburg Scotland, Aug. 1995

[20] A. Mghawish, Ossyka, I. Ottom, A Novel Approach To Enhance a University Information System, World of Computer Science and Information Technology Journal (WCSIT) ISSN: 2221-0741 Vol. 3, No. 7, 130-134, 2013 